\title{
Male breast cancer with ureteral metastasis: a case report
}

\author{
Yanbo Chen ${ }^{1,2} \wedge$ Jiannan $\mathrm{Wu}^{1,2}$, Tingting $\mathrm{Hu}^{1,2}$, Juanjuan Wang ${ }^{1,3}$, Fengxi $\mathrm{Su}^{1,2}$ \\ ${ }^{1}$ Guangdong Provincial Key Laboratory of Malignant Tumor, Epigenetics and Gene Regulation, Sun Yat-sen Memorial Hospital, Sun Yat-sen \\ University, Guangzhou, China; ${ }^{2}$ Su Fengxi Clinic, Guangzhou, China; ${ }^{3}$ Department of Pathology, Sun Yat-sen Memorial Hospital, Sun Yat-sen \\ University, Guangzhou, China \\ Correspondence to: Fengxi Su. Yingfeng Road, 33th, Haizhu District, Guangzhou 510000, China. Email: fengxisu@vip.163.com.
}

\begin{abstract}
Breast cancer is rare in men and there is no report of male breast cancer (MBC) with ureteral metastasis. In this study, we report the first case of MBC with ureteral metastasis. A 60-year-old man was diagnosed with triple negative breast cancer (TNBC) with local lymph nodes metastasis (TNM stage: T4N3M0). After surgery, chemotherapy and radiotherapy he was diagnosed with ureter metastasis because of hematuria. This patient took a Precitype gene test (immune index and PAM50) after several lines of treatment and the result indicated that this was a Luminal A subtype case as well as HER-2 mRNA positive, which was quite different from his immunohistochemical staining. Because of his poor condition and he could not tolerate chemotherapy, we adjusted his therapeutic regimen with endocrine therapy and antiHER-2 therapy according to the gene expression analysis with the informed consent of the patient and his families. However, it seemed that there was no obvious efficacy and he passed away five months later. In our opinion, MBC patients with urinary symptoms should be considered for the possibility of metastasis although urinary metastasis in breast cancer is rare. We still need more research about gene expression analysis and more evidence of treatment recommendations for MBC.
\end{abstract}

Keywords: Male breast cancer (MBC); ureteral metastasis; gene expression analysis; case report

Submitted Nov 30, 2020. Accepted for publication Jan 14, 2021.

doi: 10.21037/apm-20-2374

View this article at: http://dx.doi.org/10.21037/apm-20-2374

\section{Introduction}

Male breast cancer $(\mathrm{MBC})$ is a rare disease with an incidence rate less than $1 \%$ of that of female breast cancer $(1,2)$. On one hand, male patients usually have later onset of disease and more advanced stage than female patients. On the other hand, male patients have lower risk of death from breast cancer than comparable female patients (3). MBC patients usually have different characteristic and distinct clinical features $(4,5)$. However, only few published data were collected from small cohorts of male patients treated at single institutions and most treatment recommendations were from the results of clinical trials that enrolled only women (6), which results that evidence of MBC treatment guideline is insufficient. Common metastasis site of breast cancer includes axillary lymph nodes, lung, liver, bone and brain while ureteral metastasis is very rare (7). Here we report an interesting MBC case with ureteral metastasis. We present the following case in accordance with the CARE reporting checklist (available at http://dx.doi.org/10.21037/ apm-20-2374).

\section{Case presentation}

This study was approved by the Medical Ethics Committee of Sun Yat-sen Memorial Hospital, Sun Yat-sen University (SYSEC-KY-KS-2019-152). Written informed consent was obtained from the patient. The study was conducted in accordance with the Declaration of Helsinki (as revised in 2013). This patient was 60 years old when diagnosed with

$\wedge$ ORCID: 0000-0002-8451-4046. 

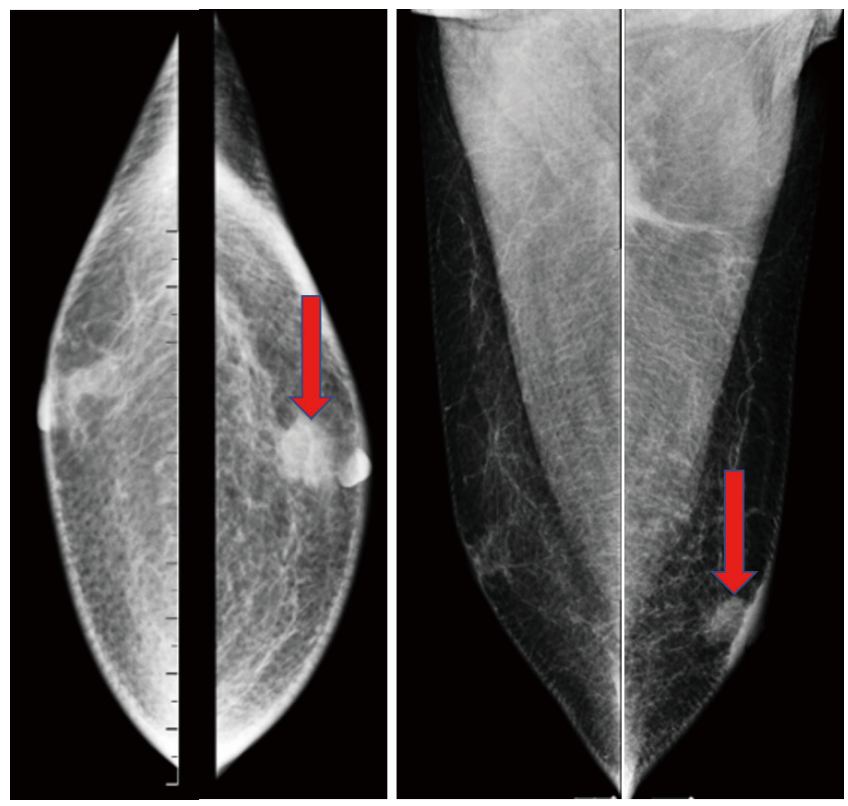

Figure 1 Mammography of the patient. The red arrows indicate lesion in the left breast.

left breast tumor with mammary radiography (Figure 1). He had a history of epilepsy and had been taking valproate orally for a long time and there was no family history of breast cancer or any other malignant tumors. After core needle biopsy, he was diagnosed with invasive ductal breast carcinoma. Further examinations indicated no distant metastasis such as liver or lung. He underwent left breast modified radical mastectomy, axillary and supraclavicular lymph node dissection in October 2016 at local hospital, and pathologic examination indicated this was an TNBC case (Invasive ductal carcinoma, T4N3M0, ER, PR and HER-2 negative, Ki-67 40\% positive, Grade III). Then he received 8 courses of chemotherapy (epirubicin, cyclophosphamide, and paclitaxel liposome) and radiotherapy (50 Gy/25 fractions).

In August 2017, he found a mass on his left upper arm and doctors of local hospital performed mass excision for him. After being confirmed of left arm metastasis, he came to our hospital for further treatment. He received chemotherapy for 6 courses (Navelbine and carboplatin) and began oral chemotherapy of capecitabine in April 2018. Unfortunately, the patient was diagnosed with ureter metastasis after middle ureter dissection and anastomosis because of hematuresis and urinary obstruction (ER, PR and HER-2 negative, Ki-67 50\% positive, Figures 2,3). After 8 courses of chemotherapy with albumin-bound paclitaxe the patient was in poor condition with severe urinary system infection. Gene expression analysis (immune index and PAM50) was taken with his primary breast tumor tissue and the test result showed he was a Luminal A subtype case and RNA expression of HER-2 gene was positive, which was totally different from his first result of immunohistochemical staining. After discussion, we gave him endocrine therapy and anti-HER-2 target therapy with aromatase inhibitors, gonadotropin-releasing hormone $(\mathrm{GnRH})$ analogue and trastuzumab with the informed consent of the patient and his families. However, it seemed that the treatment did not work and his condition was getting worse and worse and he passed away because of severe infection and multiple organ failure in April 2020.

\section{Discussion}

In this study, we introduced the first case of MBC with ureteral metastasis. His immunohistochemical character was rather different from the gene expression analysis. Although we adjusted his treatment regiment, this patient still had a poor result.

$\mathrm{MBC}$ is rather rare and the risk factors for $\mathrm{MBC}$ include demographic factors (black ethnicity, family history of breast cancer), genetic factors (germline genetic mutation, e.g., BRCA1, BRCA2, CHEK2, PALB2), environmental factors and diseases associated with hyperestrogenism (6). However, there was no family history of breast cancer in this case and the genetic test of BRCA mutation was negative. At the same time, no radiation exposure or other diseases reported as risk factors such as liver disease or testicular abnormalities or obesity in this patient. As a result, the exact cause of breast cancer in this patient was unclear and risk factors of MBC should be further studied in the future.

Research data shows that MBC risk has remained at a constant level over the past 40 years (3). Compared with female patients, male patients have later onset and more advanced disease because of lacking of awareness of early signs of breast cancer and early detection by mammography screening (8). Although overall survival of MBC is usually worse, male patients actually have a survival benefit after adjustment of life expectancy, age, time of diagnosis, stage and treatment $(3,9)$. In our study, the patient was at advanced stage when diagnosed, which leaded to his poor prognosis. In a word, much improvement in outcome of $\mathrm{MBC}$ can be achieved by improving earlier detection such as awareness and promotion of breast self-examination and development of therapy guidelines. 


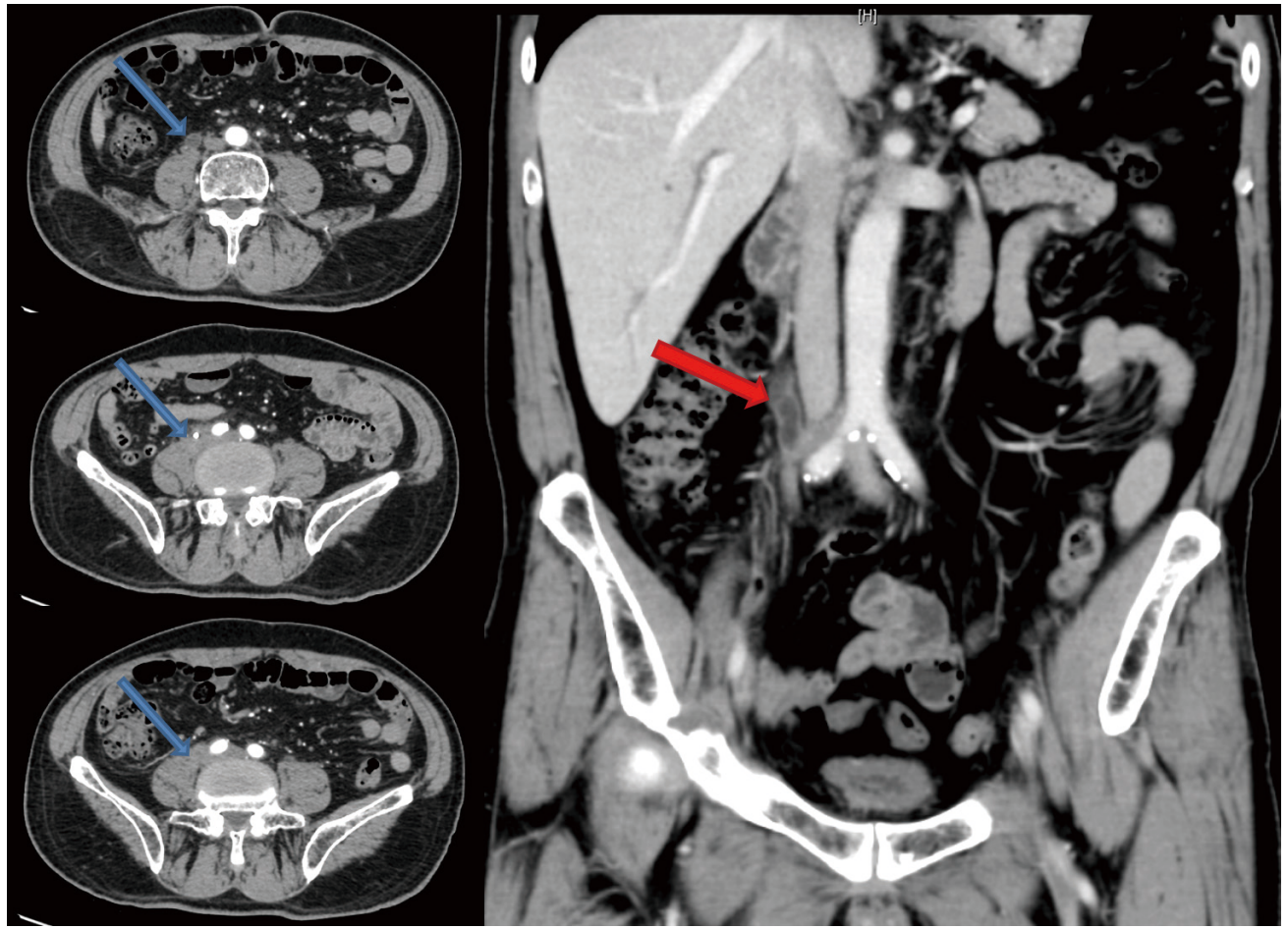

Figure 2 Breast cancer with ureteral metastasis. The blue arrows indicate metastatic region and the red arrow indicates dilated ureter.
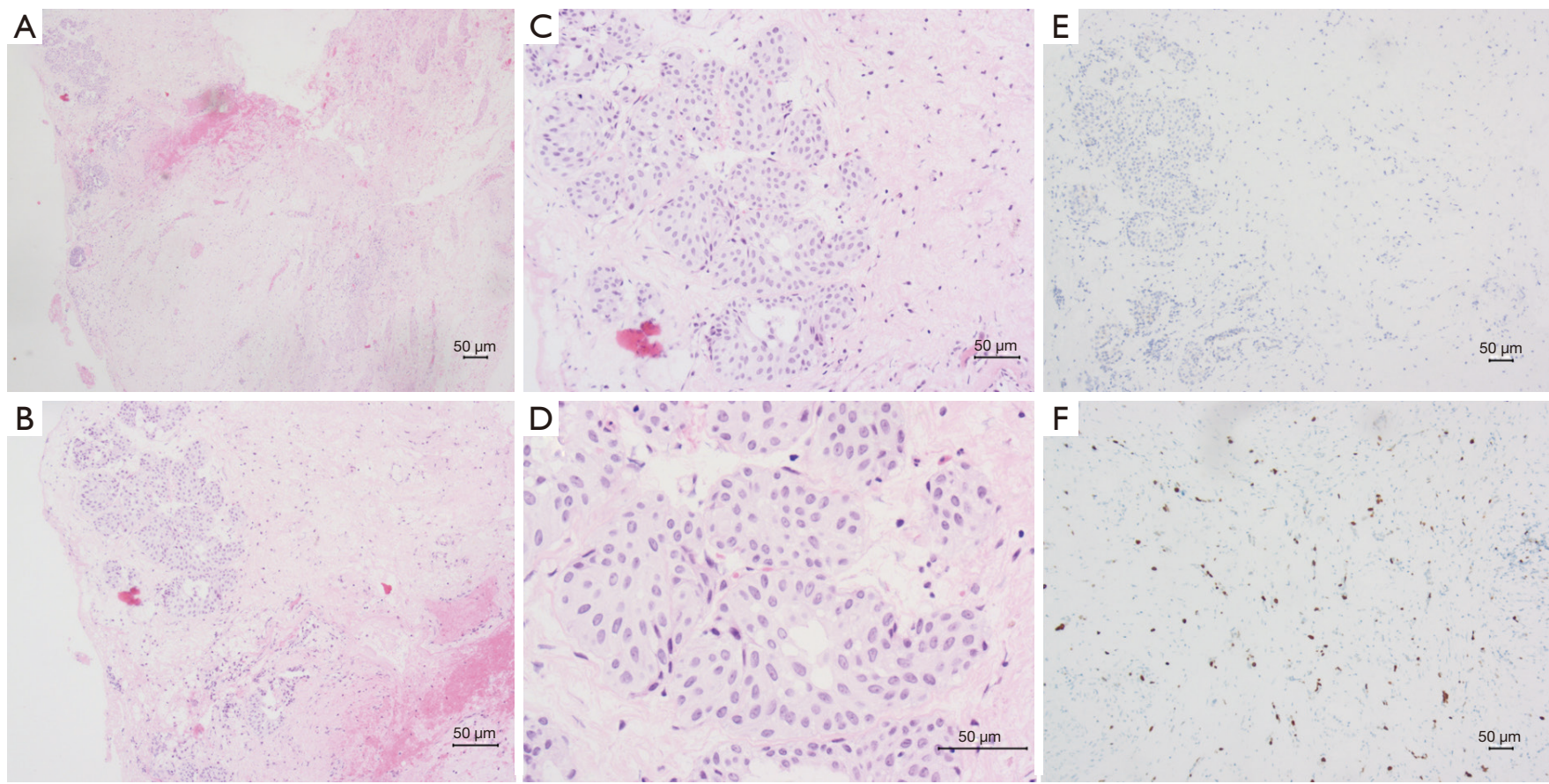

Figure $3 \mathrm{H} \& \mathrm{E}$ staining and immunohistochemical staining of the ureteral tissue shows metastasis of breast cancer. (A,B,C,D) H\&E staining shows atypical cells in ureter tissue (A: 40×, B: 100×, C: 200×, D: 400×). (E,F) Immunohistochemical staining. (E) Anti-HER-2 staining indicates HER-2 negative expression (100×). (F) Anti ki-67 staining shows about 50\% of cancer cells with ki-67 positive expression (100×). 
Breast cancer commonly metastasis to lymph nodes, lung, liver, bone or brain, and only few cases were reported metastasis to other sites such as intestine or ureter, which may be easily misdiagnosed (7). In this case, the patient developed a symptom of hematuresis, which was considered urinary tract infection or primary tumors at first. After pathological examination and considering his past history of breast cancer, he was diagnosed with ureteral metastasis and received anti-tumor therapy again. This case reminds us that any patients with urinary symptoms as well as a history of breast cancer should not be easily ruled out of cancer metastasis. Further examinations or even pathologic biopsy is necessary for these patients.

Because there is still no certain evidence such as randomized clinical trials focusing on MBC patients, treatment approaches are extrapolated from studies of treatment for women breast cancer patients (10). Adjuvant chemotherapy and HER-2 targeted therapy is strongly suggested for MBC patients who are at substantial risk for recurrence and death since observational cohort studies have suggested improved survival among them $(11,12)$. Although no randomized trials have evaluated the role of radiotherapy in men, observational studies have suggested a benefit in men with positive nodes after mastectomy $(13,14)$. Endocrine therapy is an important part of MBC management since more than $90 \%$ breast cancers in men are hormone-receptor-positive (15). However, in our case, the patient was diagnosed with triple negative breast cancer (TNBC) with ER, PR and HER-2 negative at the first time, which was really rare in $M B C$ (6).

Genomic tests, such as Oncotype DX, PAM 50, or MammaPrint are increasing used to evaluate the recurrence risk and prognosis for women with breast cancer and the likelihood that chemotherapy benefits (16-19). At the same time, gene expression analysis can also evaluate the prognostic and predictive value of breast cancer intrinsic molecular subtypes, which provides clinically relevant information beyond current pathology-based classifications (20-22). Consequently, we advised this patient to take a Precitype gene test (immune index and PAM50). This is a next generation RNA-Seq gene expression analysis of 55 genes associating with ER related genes, HER-2 related genes, proliferation related genes and basal related genes and 17 genes associated with immune genes (23). Gene expression analysis indicated that this was a Luminal A case and the RNA expression of HER-2 was positive. Previous study indicated that patients with HR-positive/HER2-negative disease with a HER2 profile may benefit from therapy of lapatinib, a dual tyrosine kinase inhibitor of epidermal growth factor receptor (EGFR) and HER-2 (24). Since his condition was bad and could not tolerate chemotherapy, we adjusted his therapy schedule with aromatase inhibitors plus GnRH analogue and trastuzumab with the informed consent of the patient and his families $(25,26)$. However, it seemed that it did not work and his condition was getting poorer. Previous research had demonstrated that those patients would have worse prognosis if their PAM50 molecular subtyping is distinct with immunohistochemical subtyping (27), which may explain this patient's poor outcome to some extent. Genomic test such as Oncotype DX is increasingly being used in the management of MBC in clinical practice (28). However, we need more long-term outcomes data to fully understand the implications of this practice.

\section{Conclusions}

To the best of our knowledge, this is the first case of MBC with ureteral metastasis reported. We still know very little about $\mathrm{MBC}$ at present because of its rather low morbidity rate. More studies about the clinicopathological and immunohistochemical features of MBC should be conducted to build an evidence base that supports future treatment recommendations for this rare disease.

\section{Acknowledgments}

We offer our thanks and respect to the patient and his families for their approval of reporting this case for medical research.

Funding: This study was supported by the National natural science foundation of China (81672619) and the Clinical Research Cultivation Project of Sun Yat-sen Memorial Hospital, Sun Yat-sen University.

\section{Footnote}

Reporting Checklist: The authors have completed the CARE reporting checklist. Available at http://dx.doi.org/10.21037/ apm-20-2374

Conflicts of Interest: All authors have completed the ICMJE uniform disclosure form (available at http://dx.doi. org/10.21037/apm-20-2374). The authors have no conflicts of interest to declare.

Ethical Statement: The authors are accountable for all 
aspects of the work in ensuring that questions related to the accuracy or integrity of any part of the work are appropriately investigated and resolved. This study was approved by the Medical Ethics Committee of Sun Yatsen Memorial Hospital, Sun Yat-sen University (SYSECKY-KS-2019-152). Written informed consent was obtained from the patient. The study was conducted in accordance with the Declaration of Helsinki (as revised in 2013).

Open Access Statement: This is an Open Access article distributed in accordance with the Creative Commons Attribution-NonCommercial-NoDerivs 4.0 International License (CC BY-NC-ND 4.0), which permits the noncommercial replication and distribution of the article with the strict proviso that no changes or edits are made and the original work is properly cited (including links to both the formal publication through the relevant DOI and the license). See: https://creativecommons.org/licenses/by-nc-nd/4.0/.

\section{References}

1. Czene K, Bergqvist J, Hall P, et al. How to treat male breast cancer. Breast 2007;16 Suppl 2:S147-54.

2. Siegel RL, Miller KD, Jemal A. Cancer statistics, 2018. CA Cancer J Clin 2018;68:7-30.

3. Miao H, Verkooijen HM, Chia KS, et al. Incidence and outcome of male breast cancer: an international population-based study. J Clin Oncol 2011;29:4381-6.

4. Anderson WF, Jatoi I, Tse J, et al. Male breast cancer: a population-based comparison with female breast cancer. J Clin Oncol 2010;28:232-9.

5. Cardoso F, Bartlett JMS, Slaets L, et al. Characterization of male breast cancer: results of the EORTC 10085/ TBCRC/BIG/NABCG International Male Breast Cancer Program. Ann Oncol 2018;29:405-17.

6. Giordano SH. Breast Cancer in Men. N Engl J Med 2018;378:2311-20.

7. Xie J, Ying YY, Xu B, et al. Metastasis pattern and prognosis of male breast cancer patients in US: a population-based study from SEER database. Ther Adv Med Oncol 2019;11:1758835919889003.

8. Goss PE, Reid C, Pintilie M, et al. Male breast carcinoma: a review of 229 patients who presented to the Princess Margaret Hospital during 40 years: 1955-1996. Cancer 1999;85:629-39.

9. Scott-Conner CE, Jochimsen PR, Menck HR, et al. An analysis of male and female breast cancer treatment and survival among demographically identical pairs of patients.
Surgery 1999;126:775-80; discussion 80-1.

10. Korde LA, Zujewski JA, Kamin L, et al. Multidisciplinary meeting on male breast cancer: summary and research recommendations. J Clin Oncol 2010;28:2114-22.

11. Patel HZ 2nd, Buzdar AU, Hortobagyi GN. Role of adjuvant chemotherapy in male breast cancer. Cancer 1989;64:1583-5.

12. Hassett MJ, Somerfield MR, Baker ER, et al. Management of Male Breast Cancer: ASCO Guideline. J Clin Oncol 2020;38:1849-63.

13. Madden NA, Macdonald OK, Call JA, et al. Radiotherapy and Male Breast Cancer: A Population-based Registry Analysis. Am J Clin Oncol 2016;39:458-62.

14. Eggemann H, Ignatov A, Stabenow R, et al. Male breast cancer: 20-year survival data for post-mastectomy radiotherapy. Breast Care (Basel) 2013;8:270-5 .

15. Fentiman IS, Fourquet A, Hortobagyi GN. Male breast cancer. Lancet 2006;367:595-604.

16. Grenader T, Yerushalmi R, Tokar M, et al. The 21gene recurrence score assay (Oncotype DX) in estrogen receptor-positive male breast cancer: experience in an Israeli cohort. Oncology 2014;87:1-6.

17. Petkov VI, Miller DP, Howlader N, et al. Breast-cancerspecific mortality in patients treated based on the 21-gene assay: a SEER population-based study. NPJ Breast Cancer 2016;2:16017.

18. Cardoso F, van't Veer LJ, Bogaerts J, et al. 70-Gene Signature as an Aid to Treatment Decisions in Early-Stage Breast Cancer. N Engl J Med 2016;375:717-29.

19. Sestak I, Cuzick J, Dowsett M, et al. Prediction of late distant recurrence after 5 years of endocrine treatment: a combined analysis of patients from the Austrian breast and colorectal cancer study group 8 and arimidex, tamoxifen alone or in combination randomized trials using the PAM50 risk of recurrence score. J Clin Oncol 2015;33:916-22.

20. Prat A, Perou CM. Deconstructing the molecular portraits of breast cancer. Mol Oncol 2011;5:5-23.

21. Parker JS, Mullins M, Cheang MC, et al. Supervised risk predictor of breast cancer based on intrinsic subtypes. J Clin Oncol 2009;27:1160-7.

22. Prat A, Pineda E, Adamo B, et al. Clinical implications of the intrinsic molecular subtypes of breast cancer. Breast 2015;24 Suppl 2:S26-35.

23. Ohnstad HO, Borgen E, Falk RS, et al. Prognostic value of PAM50 and risk of recurrence score in patients with early-stage breast cancer with long-term follow-up. Breast Cancer Res 2017;19:120. 
24. Prat A, Cheang MC, Galvan P, et al. Prognostic Value of Intrinsic Subtypes in Hormone Receptor-Positive Metastatic Breast Cancer Treated With Letrozole With or Without Lapatinib. JAMA Oncol 2016;2:1287-94.

25. Eggemann H, Ignatov A, Smith BJ, et al. Adjuvant therapy with tamoxifen compared to aromatase inhibitors for 257 male breast cancer patients. Breast Cancer Res Treat 2013;137:465-70.

26. Zagouri F, Sergentanis TN, Koutoulidis V, et al. Aromatase inhibitors with or without gonadotropin-

Cite this article as: Chen Y, Wu J, Hu T, Wang J, Su F. Male breast cancer with ureteral metastasis: a case report. Ann Palliat Med 2021;10(7):8346-8351. doi: 10.21037/apm-20-2374 releasing hormone analogue in metastatic male breast cancer: a case series. Br J Cancer 2013;108:2259-63.

27. Kim HK, Park KH, Kim Y, et al. Discordance of the PAM50 Intrinsic Subtypes Compared with Immunohistochemistry-Based Surrogate in Breast Cancer Patients: Potential Implication of Genomic Alterations of Discordance. Cancer Res Treat 2019;51:737-47.

28. Yadav S, Karam D, Bin Riaz I, et al. Male breast cancer in the United States: Treatment patterns and prognostic factors in the 21st century. Cancer 2020;126:26-36. 